\title{
Effect of Surfactant Substitution on Lung Effluent Phospholipids in Respiratory Distress Syndrome: Evaluation of Surfactant Phospholipid Turnover, Pool Size, and the Relationship to Severity of Respiratory Failure
}

\author{
MIKKO HALLMAN, T. ALLEN MERRITT, MAIJA POHJAVUORI, AND LOUIS GLUCK \\ Children's Hospital, University of Helsinki, 00290 Helsinki, Finland [M.H., M.P.] and Department of Pediatrics, \\ University of California, San Diego, La Jolla, California 92103 [T.A.M., L.G.]
}

\begin{abstract}
The turnover and pool size of surfactant has been studied in animals, but there is little similar information in humans. In the present investigation lung effluent phospholipids were studied in 29 small preterm infants with severe RDS. Thirteen were treated with mechanical ventilation, and 16 additionally received natural human surfactant. The first dose (60 mg surfactant/kg body wt) was given between 2 and $10 \mathrm{~h}$ of age, and the surfactant was given again if there was an insufficient response. Together $\mathbf{2 6 0}$ aspirates, recovered during routine suctioning of the airways, were analyzed for phospholipids. Phosphatidylglycerol, present only in exogenous surfactant, was used as a specific marker to estimate the apparent pool size and the half-life of surfactant phospholipid. In addition, the saturated phosphatidylcholine/sphingomyelin ratios were correlated with the ventilatory index (mean airway pressure $x$ fractional inspiratory oxygen/arterial oxygen tension). There was a linear correlation between the ventilatory index and the saturated phosphatidylcholine/ sphingomyelin $(r \sim \mathbf{- 0 . 7 0})$ but no consistent correlation between the ventilatory index and the amount of phospholipids in the aspirate. The saturated phosphatidylcholine/ sphingomyelin ratio increased during the surfactant-induced remission of respiratory failure, decreased during the relapse of respiratory failure (present among $50 \%$ of the surfactant-treated infants), and increased again during the recovery. The control infants tended to have lower saturated phosphatidylcholine/sphingomyelin ratios during the first week than the surfactant-treated infants. The recipients of surfactant had slightly more severe lung disease than the controls, when the results were adjusted by covariance to remove the differences in the saturated phosphatidylcholine/sphingomyelin ratio. Exogenous surfactant increased the apparent endogenous pool size at least fivefold. The apparent half-life of phosphatidylglycerol was $30 \mathrm{~h}(20-36 \mathrm{~h})$. The half-life was independent of the amount of exogenous surfactant (60 versus $120 \mathrm{mg} / \mathrm{kg})$. Therefore, the apparent turnover rate after 120 was higher than after $60 \mathrm{mg} / \mathrm{kg}$ surfactant $(p<0.01)$. (Pediatr Res 20: 1228-1235, 1986)
\end{abstract}

Received January 27, 1986: accepted July 3, 1986

Correspondence Mikko Hallman, M.D., Children's Hospital, University of helsinki, Stenbäckinkatu 11, SF-00290 Helsinki, Finland.

This work was supported by grants from the Finnish Academy, the Sigrid Jusellius Foundation (M.H.), and the National Institutes of Health Grant HD 16292 (T.A.M.).

\begin{abstract}
Abbreviations
RDS, respiratory distress syndrome PG, phosphatidylglycerol SPC, saturated phosphatidylcholine $\mathrm{FIO}_{2}$, fractional inspiratory oxygen PI, phosphatidylinositol
\end{abstract}

Surfactant substitution is a promising way to treat or prevent RDS (1-3). In human trials extracts from animal lung, supplemented with synthetic lipids, synthetic phospholipids, lipid extracts from animal lung lavage, or natural human surfactant from amniotic fluid have been applied to the airways. Surfactant supplementation has decreased oxygen and respirator requirements and reduced the incidence of death and/or bronchopulmonary dysplasia in severe RDS but has not eliminated serious pulmonary morbidity altogether (4). The pharmacodynamic aspects of surfactant supplementation are insufficiently known, and potential side effects such as toxicity, immunological complications, deterioration of the cardiopulmonary system due to increased left-to-right circulatory shunt through patent ductus arteriosus, or inhibition of endogenous surfactant remain to be further evaluated (4).

There is a striking increase in surfactant during late fetal development as studied in rodents, lambs, and monkeys (5). The surface activity (6) and the recovery of phosphatidylcholine (7) in ex vivo lung lavage are low in hyaline membrane disease. Although the pool size of human surfactant has not been quantitated in vivo, the measurements of the lecithin/sphingomyelin ratio, PG, SPC, surface activity, microviscosity, and other tests are important in prediction of fetal lung maturity (8) or in diagnosis of surfactant abnormalities after birth (9-11).

Only a small and variable fraction of extracellular surfactant can be recovered during a small volume in vivo lung lavage. According to animal studies there is a rapid bidirectional flux of intact surfactant phospholipids between intracellular lamellar bodies and the surface of the airways (12-14). These interactions between intra- and extracellular surfactant can be about one order of magnitude faster than the apparent rate of surfactant synthesis and secretion (13). Therefore, the phospholipid pools in intracellular lamellar bodies and in the alveolar lavage may be effectively mixed $(12,15)$. Since the quality of phospholipids in a small volume in vivo lavage is similar to that in quantitative ex vivo lung lavage (16), it may be possible to evaluate the pool 
size and the turnover of surfactant by means of a surfactant size and the turnover of surfactant by means of a surfactant marker introduced to the airways.

The turnover of surfactant has been extensively studied in animals using phospholipid and protein precursors (12-14, 1720 ). Rodents tend to have a shorter biological half-life of phosphatidylcholine than lambs $(18,21,22)$. Furthermore, the halflives of phospholipids tend to be slower in newborns than in adults $(19,22)$. These phylogenic and ontogenic differences underline the necessity to study kinetics of human surfactant in more detail, particularly in serious lung diseases involving the surfactant system. The present investigation is an attempt to analyze the quality, quantity, and turnover of surfactant phospholipids among the small preterm infants who received natural homologous surfactant in a randomized trial to treat severe RDS.

\section{MATERIALS AND METHODS}

The patients participated in a dual center randomized prospective trial (23). Infants less than $10 \mathrm{~h}$ old, birth $w \mathrm{t}<1500 \mathrm{~g}$, and who had RDS were eligible when they required $>60 \%$ oxygen and intermittent mandatory ventilation producing mean airway pressures of at least $8 \mathrm{~cm} \mathrm{H} \mathrm{H}_{2} \mathrm{O}$. Sealed sequentially numbered envelopes with random numbers indicating either surfactant treatment or conventional ventilation and containing consent forms were opened after parent(s) consented to their infant's participation.

Natural human surfactant isolated from amniotic fluid (20 $\mathrm{mg} / \mathrm{ml})$ was vortexed in $0.6 \%$ saline. Surfactant $(60 \mathrm{mg} / \mathrm{kg}$ or at least $60 \mathrm{mg}$ in $3 \mathrm{ml} 0.6 \%$ saline) was injected as a bolus through a 5 French catheter inserted through the endotracheal tube positioned above the carina. After administration the infant was ventilated manually for 30-60 s, gently rocked from side to side and cephalad to caudad. Thereafter the infant was reconnected to the ventilator at pretreatment settings. No placebo was used. Retreatment once or twice with a similar dose of surfactant was permitted between 2 and $28 \mathrm{~h}$ after the first dose. Retreatment was indicated when $\mathrm{FIO}_{2}$ requirements reached $0.5-0.8$ or the peak inspiratory pressure increase of $5 \mathrm{~cm} \mathrm{H}_{2} \mathrm{O}$ was necessary.

The ventilatory management was consistent between the two institutions. The airway pressures were measured from the proximal airway using a Pneumogard (Novametrix, Wallingford, CT). The attempt was to initially manage the patients using mean airway pressures of $8-10 \mathrm{~cm} \mathrm{H}_{2} \mathrm{O}$. The airway pressures were decreased when an $\mathrm{FIO}_{2}$ of 0.8 was sufficient to maintain arterial $\mathrm{PO}_{2}$ between 50 and $70 \mathrm{~mm} \mathrm{Hg}$. The respirator settings were adjusted to maintain arterial $\mathrm{PCO}_{2}$ between 35 and $55 \mathrm{~mm} \mathrm{Hg}$. The ventilatory index defined as the product of the mean airway pressure $\left(\mathrm{cm} \mathrm{H}_{2} \mathrm{O}\right)$ and the $\mathrm{FIO}_{2}$ concentration divided by postductal arterial $\mathrm{pO}_{2}$ was calculated.

The airways were routinely suctioned every 4-8 h, during intubation. Normal saline $(1.0-2.0 \mathrm{ml})$ was injected through the endotracheal tube. The patient was briefly ventilated manually, followed by suctioning of the airways $1 \mathrm{~cm}$ distal to the tip of the endotracheal tube. The two groups were comparably treated with respect to airway management. Any fluid that was recovered was collected in a Leuken's trap. To rinse the aspirates from the side wall of the catheter, $0.5 \mathrm{ml}$ saline was aspirated through the catheter into the trap. The lung effluent was kept at $4^{\circ} \mathrm{C}$ for no longer than $20 \mathrm{~h}$ and centrifuged at $150 \times g$ for $10 \mathrm{~min}$. The supernatant was recovered and frozen at $-20^{\circ} \mathrm{C}$ for no longer than 3 months before the phospholipid analysis. All tracheal aspirates, recovered within 4 days after exogenous surfactant, were analyzed for phospholipids. Otherwise one to three daily tracheal aspirates were available for phospholipid analysis during the first week.

The phospholipids were quantitatively measured as described previously (12). Each sample was analyzed for total phospholipid content and for distribution of individual phospholipids. Two or more successive aspirates were combined if the amount of the total phospholipids was $<200 \mathrm{nmol}$. After two-dimensional thinlayer chromatography the phosphorus contents of phosphatidylcholine, PI, PG, bis-(monoacylglycerol) phosphate, phosphatidylethanolamine, phosphatidylserine, sphingomyelin, and lysophosphatidylcholine were measured. SPC was analyzed by a modification of the procedure of Mason et al. $(12,24)$.

The apparent half-life of PG, as a component of exogenous natural human surfactant, was estimated on the basis of exponential decay data by least-squares method (25). PG recovered during suctioning of the airways was expressed on the basis of the following references: 1) the sum of PG and PI, 2) SPC, 3) total phospholipid, and 4) sphingomyelin.

The pool into which the exogenous surfactant phospholipids were distributed was calculated on the basis of the Fick principle, knowing that there was no detectable PG lung effluent before exogenous surfactant (11). The distribution at zero time was calculated by extrapolating the line describing the exponential decay data of PG. Therefore the apparent total pool size of surfactant phospholipids equalled the amount of exogenous surfactant phospholipids $\times$ PG in exogenous surfactant (\% of surfactant phospholipids)/calculated PG in lung effluent at zero time (\% of surfactant phospholipids).

Results were expressed as means \pm SE. The statistical analyses were performed using BMDP statistical software, University of California, Berkeley. The difference between the groups was evaluated using analysis of variance and the $t$ test. The severity of RDS was analyzed by covariance adjustment to eliminate the influence of the SPC/sphingomyelin ratio and the postnatal age (BMDP IV).

\section{RESULTS}

All infants participated in a randomized dual center trial on surfactant substitution in severe RDS (23). Together 179 specimens from 16 surfactant-treated and 81 specimens from 13 control infants were analyzed. In 22 cases (eight surfactant, 14 controls) two or more aspirates were combined because of insufficient quantity of phospholipid. From the remaining 16 infants there were not enough tracheal aspirates available for the phospholipid analysis because of either early death (five infants) the specimens being used for other studies. There were no significant differences in the birth weight $(1076 \pm 53 \mathrm{~g})$, gestational age $(28.1 \pm 0.6 \mathrm{wk})$, Apgar scores, or incidence of obstetric complications between these two groups of small preterm infants with RDS.

Effect of surfactant substitution on distribution of lung effluent phospholipids. Table 1 shows the distribution of various phospholipid classes and the recovery of total phospholipid per aspirate during the first week. There were no detectable differences in the phospholipids before exogenous surfactant. Administration of exogenous surfactant increased the percentage of surfactant phospholipids, especially PG and SPC, and decreased the "membranous nonsurfactant" phospholipids (mainly sphingomyelin and phosphatidylserine). Of the surfactant phospholipids only PG strikingly decreased later. The control infants revealed a similar but much more gradual changes in lung effluent, although there was virtually no evidence of surfactant PG during the first week. Even 1 wk after exogenous surfactant SPC/ sphingomyelin ratio was higher among the recipients of surfactant than among the controls.

Lung effluent phospholipids and the severity of RDS. The severity of the respiratory failure during the respirator course was evaluated on the basis of the ventilatory index, i.e. mean airway pressure $\times \mathrm{FIO}_{2} /$ arterial $\mathrm{pO}_{2}$. The lung effluent phospholipids were correlated with the ventilatory index only when the product of $\mathrm{FIO}_{2}$ and mean airway pressure remained within $\pm 10 \%$ of the mean during $\pm 2 \mathrm{~h}$ from suctioning of the airways. When the ventilatory index was unstable, the result was not included in the analysis.

SPC/sphingomyelin ratio was correlated with the ventilatory 
Table 1. Phospholipids of lung effluent during the course of RDS; effect of surfactant substitution*

\begin{tabular}{|c|c|c|c|c|c|c|c|c|c|c|c|c|c|c|}
\hline & \multicolumn{2}{|c|}{$\begin{array}{c}<10 \mathrm{~h} \text { or } \\
\text { pretreatment }\end{array}$} & \multicolumn{3}{|c|}{$10-24 \mathrm{H}$} & \multicolumn{3}{|c|}{2 Days } & \multicolumn{3}{|c|}{4 Days } & \multicolumn{3}{|c|}{7 Days } \\
\hline & $\mathrm{C}$ & S & $\mathrm{C}$ & $\mathrm{S}$ & $p$ & $\mathrm{C}$ & $S$ & $p$ & $\mathrm{C}$ & $S$ & $p$ & $\mathrm{C}$ & S & $p$ \\
\hline$n$ & 12 & 14 & 8 & 15 & & 10 & 13 & & 6 & 10 & & 8 & 7 & \\
\hline \multicolumn{15}{|l|}{$\%$ Distribution } \\
\hline \multirow[t]{2}{*}{ Phosphatidylcholine } & 65.9 & 63.0 & 70.9 & 79.9 & 0.001 & 76.4 & 79.5 & & 78.0 & 79.1 & & 78.3 & 79.4 & \\
\hline & \pm 1.4 & \pm 2.3 & \pm 1.1 & \pm 1.0 & & \pm 1.3 & \pm 0.9 & & \pm 0.4 & \pm 0.4 & & \pm 0.5 & \pm 0.6 & \\
\hline \multirow[t]{2}{*}{ Sphingomyelin } & 11.5 & 12.5 & 9.4 & 2.6 & 0.001 & 6.0 & 3.1 & 0.01 & 4.3 & 2.8 & 0.001 & 3.9 & 2.4 & 0.05 \\
\hline & \pm 0.5 & \pm 1.0 & \pm 1.1 & \pm 0.3 & & \pm 0.7 & \pm 0.3 & & \pm 0.2 & \pm 0.2 & & \pm 0.4 & \pm 0.2 & \\
\hline \multirow[t]{2}{*}{ PI } & 7.0 & 6.9 & 6.4 & 6.7 & & 7.3 & 8.5 & & 9.1 & 10.4 & & 9.9 & 11.2 & \\
\hline & \pm 0.3 & \pm 0.3 & \pm 0.4 & \pm 0.5 & & \pm 0.4 & \pm 0.5 & & \pm 0.2 & \pm 0.6 & & \pm 0.6 & \pm 0.5 & \\
\hline \multirow[t]{2}{*}{ Phosphatidylglycerol } & 0.0 & 0.0 & 0.0 & 4.4 & 0.001 & 0.2 & 2.3 & 0.001 & 0.4 & 0.7 & & 0.2 & 0.1 & \\
\hline & \pm 0.0 & \pm 0.0 & \pm 0.0 & \pm 0.5 & & \pm 0.0 & \pm 0.2 & & \pm 0.0 & \pm 0.1 & & \pm 0.1 & \pm 0.1 & \\
\hline \multirow{2}{*}{ Phosphatidylethanolamine } & 7.1 & 8.6 & 6.7 & 3.5 & 0.02 & 6.1 & 3.8 & 0.001 & 4.8 & 3.8 & & 4.2 & 3.8 & \\
\hline & \pm 0.7 & \pm 0.9 & \pm 1.1 & \pm 0.2 & & \pm 0.3 & \pm 0.3 & & \pm 0.8 & \pm 0.3 & & \pm 0.2 & \pm 0.6 & \\
\hline \multirow[t]{2}{*}{ Bis(monoacylglycerol)phosphate } & 0.2 & 0.1 & 0.3 & 1.0 & 0.001 & 0.4 & 0.6 & & 0.1 & 0.3 & & 0.3 & 0.3 & \\
\hline & \pm 0.0 & \pm 0.1 & \pm 0.0 & \pm 0.1 & & \pm 0.1 & \pm 0.1 & & \pm 0.1 & \pm 0.1 & & \pm 0.1 & \pm 0.2 & \\
\hline \multirow[t]{2}{*}{ Phosphatidylserine } & 7.5 & 8.2 & 5.6 & 1.2 & 0.001 & 2.8 & 1.2 & 0.001 & 1.9 & 1.7 & & 1.9 & 1.8 & \\
\hline & \pm 0.8 & \pm 0.3 & \pm 0.9 & \pm 0.2 & & \pm 0.2 & \pm 0.2 & & \pm 0.2 & \pm 0.3 & & \pm 0.2 & \pm 0.3 & \\
\hline \multirow[t]{2}{*}{ Lysophosphatidylcholine } & 0.8 & 0.7 & 0.7 & 0.7 & & 0.8 & 1.0 & & 1.3 & 1.2 & & 1.2 & 1.0 & \\
\hline & \pm 0.5 & \pm 0.1 & \pm 0.1 & \pm 0.1 & & \pm 0.1 & \pm 0.1 & & \pm 0.4 & \pm 0.2 & & \pm 0.4 & \pm 0.2 & \\
\hline \multirow[t]{2}{*}{ Saturated PI/sphingomyelin } & 1.8 & 1.8 & 2.9 & 19.8 & 0.001 & 7.1 & 15.0 & 0.001 & 7.6 & 15.4 & 0.001 & 11.0 & 17.5 & 0.05 \\
\hline & \pm 0.2 & \pm 0.1 & \pm 0.5 & \pm 1.4 & & \pm 1.3 & \pm 1.7 & & \pm 0.9 & \pm 1.9 & & \pm 1.8 & \pm 1.7 & \\
\hline \multirow{2}{*}{$\begin{array}{l}\text { Recovery of phospholipid in a tra- } \\
\text { cheal aspirate }(\mathrm{nmol})\end{array}$} & 95 & 80 & 202 & 863 & $<0.005$ & 226 & 697 & 0.01 & 487 & 494 & & 283 & 409 & \\
\hline & \pm 49 & \pm 31 & \pm 73 & \pm 143 & & \pm 26 & \pm 145 & & \pm 131 & \pm 98 & & \pm 24 & \pm 88 & \\
\hline
\end{tabular}

* Lung effluent was recovered during routine suctioning of the trachea as described in "Methods." Lung effluents within $<4 \mathrm{~h}$ after exogenous surfactant were excluded from these results. Results are expressed as means $\pm \mathrm{SE}$. C, control; S, surfactant.


Fig. 1. Correlation between severity of respiratory failure and SPC/sphingomyelin ratio. This correlation was performed only when the product of mean airway pressure and $\mathrm{FIO}_{2}$ remained within $\pm 10 \%$ of the mean during $\pm 2 \mathrm{~h}$ from recovery of tracheal aspirate. Individual cases (thin lines) represent 3-11 analyses each. Only cases with asterisks have a worse correlation coefficient than those of pooled data (arrow).

index. The linear regression analysis yielded a significant inverse correlation both in surfactant-treated and control infants (Fig. 1). Although the individual correlation coefficients were generally good (absolute mean 0.826, range 0.372-0.997), there was a considerable scatter in the regression coefficients and in the intercepts. There was a poor correlation between the ventilatory index and the recovery of total phospholipid per aspirate $(r=$ $-0.389, p<0.01$ for controls; $r=-0.124, p>0.1$ for recipients of surfactant).

Table 2 shows the adjusted means of the ventilatory indexes and comparison between surfactant-treated and control infants. When adjusted for the SPC/sphingomyelin ratio the substituted infants tended to have a more severe lung disease than the controls. This was not evident before surfactant supplementation (data not shown). Therefore exogenous surfactant seemed to improve the surfactant indexes more than the severity of the respiratory failure. This became less evident when the postnatal age was considered as an additional covariate.

The course of RDS of the substituted infants was divided into presurfactant, remission, relapse, and recovery phases. The remission of respiratory failure always occurred immediately after exogenous surfactant. During remission the ventilatory index was at least $50 \%$ lower than shortly before exogenous surfactant. Relapse was evident when the ventilatory index increased sharply 
Table 2. Dependence of ventilatory index on lung effluent phospholipids and on postnatal age; covariance adjustment*

\begin{tabular}{|c|c|c|c|c|c|}
\hline \multirow[b]{3}{*}{ Covariance adjustment } & \multicolumn{4}{|c|}{ Ventilatory index $\left(\mathrm{cm} \mathrm{H}_{2} \mathrm{O} / \mathrm{mm} \mathrm{Hg}\right)$} & \multirow[b]{3}{*}{$p$} \\
\hline & \multicolumn{2}{|c|}{ Adjusted mean } & \multicolumn{2}{|c|}{ SE } & \\
\hline & Surfactant & Control & Surfactant & Control & \\
\hline No & 0.064 & 0.080 & 0.005 & 0.007 & 0.05 \\
\hline SPC/sphingomyelin & 0.078 & 0.056 & 0.004 & 0.005 & 0.002 \\
\hline SPC/sphingomyelin and postnatal age & 0.074 & 0.063 & 0.003 & 0.004 & 0.03 \\
\hline
\end{tabular}

$*$ Results are based on 163 lung effluents analyzed for phospholipids and a concomitant evaluation of the ventilatory index $\left(\mathrm{FiO}_{2} \times \mathrm{mean}\right.$ airway pressure/arterial $\mathrm{pO}_{2}$ ). Lung effluents that were recovered within $<4 \mathrm{~h}$ after surfactant supplementation were excluded from the present analysis.

(within $2 \mathrm{~h}$ ) and consistently by $\geq 60 \%$ from the present during remission. The recovery was defined as a consistent decrease in the ventilatory index by at least $40 \%$ from that during the relapse. Only eight infants had a relapse. Seven only had one dose of surfactant before the relapse. Three of the eight infants were retreated with surfactant during the relapse, and the ventilatory index improved. In eight infants there was no relapse, and the remission continued to recovery. Five of these eight infants received one additional dose of surfactant during remission, because the infants' respiratory failure remained severe enough to permit a second dose (23). SPC/sphingomyelin ratio was correlated with the ventilatory index during the successive phases of RDS, modified by exogenous surfactant (Fig. 2). There was always a significant inverse correlation between the ventilatory index and the SPC/sphingomyelin ratio. However, the correlation was weak among the infants whose remission of the respiratory failure was not complicated by relapse.

Apparent biological half-life of phosphatidylglycerol. The distribution between the acidic surfactant phospholipids (PG and PI) and SPC revealed no detectable change throughout the respiratory course, regardless of whether the exogenous surfactant was given (data not shown). However, there were striking changes in PG and PI. Figure 3 shows the disappearance of PG among the lung effluent phospholipids in two representative cases. PG was expressed on the basis of SPC, sum of PG and PI, total phospholipid, and sphingomyelin, respectively. Case 1 required a second dose shortly after the first dose because the $\mathrm{FIO}_{2}$ requirements did not decrease below 0.5 . Respiratory function continued to improve after the second dose, and there was no relapse. In case 1 the apparent half-life of PG was well defined. Conversely, patient 5 had a relapse and was retreated $40 \mathrm{~h}$ after the first dose. The second dose improved respiratory function, and there was no more relapse. In this case the apparent half-life was ambiguous.

The specimens that were recovered within less than $4 \mathrm{~h}$ after surfactant contained more PG than expected on the basis of exponential regression analysis (data not shown). This suggests nonuniform distribution of phospholipids. Therefore only lung effluents recovered 4 or more h after surfactant substitution were included in the present analysis.

Table 3 shows the apparent biological half-lives among the 10 cases of RDS treated with surfactant. Six cases were not evaluated for the half-life because of an insufficient number of specimens $(n \leq 4)$ between 4 and $160 \mathrm{~h}$ after exogenous surfactant. In the five cases with relapse of respiratory failure (cases 2, 5a, 7-9), the apparent half-life was shorter when PG was expressed on the basis of nonsurfactant rather than surfactant reference. However, for the rest of the cases that had continuously high SPC/sphingomyelin ratio and no relapse, the four estimates of the half-lives gave consistent results. The apparent biological half-life ranged between 20 and $36 \mathrm{~h}$. The cases that got two doses of surfactant did not have a longer half-life of PG $(32 \pm 2 \mathrm{~h})$ than those who got a single dose of surfactant $(30 \pm 1 \mathrm{~h})$.

Apparent pool size of surfactant phospholipids. The size of the phospholipid pool into which the surfactant phospholipids (phosphatidylcholine, PI, PG) were distributed was evaluated on the

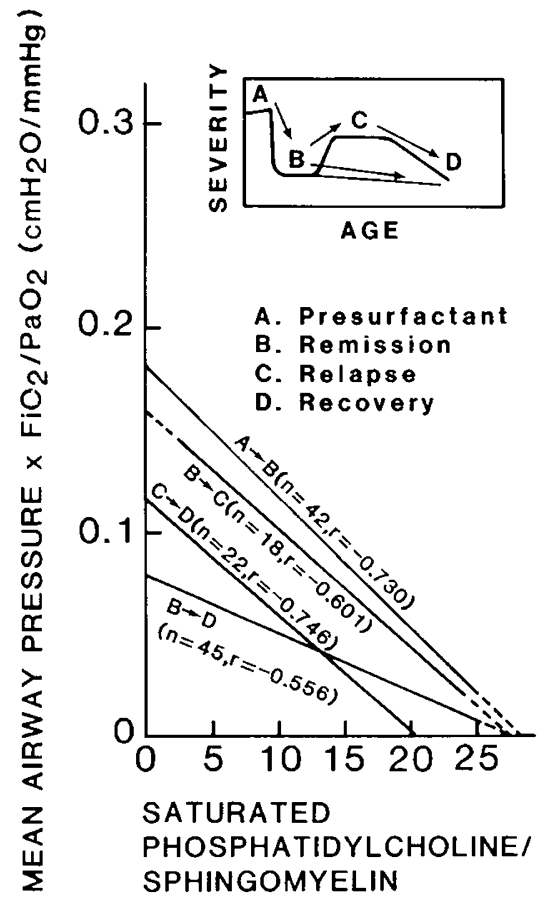

Fig. 2. Correlation between severity of respiratory failure (ventilatory index) and tracheal aspirate SPC/sphingomyelin ratios among recipients of surfactant. Longitudinal course of RDS was divided into presurfactant, remission, relapse, and recovery phases (see "Results"). Relapse was evident when the ventilatory index increased by at least $60 \%$ from the baseline present during remission. Recovery was defined as a consistent decrease of the ventilatory index by at least $40 \%$ from base line present during relapse. On the basis of this definition 8 of the 16 patients had no relapse. Regression lines show the correlation between the ventilatory index and the phospholipid index during the course of RDS, as defined above. Number or infants (specimens): $A \rightarrow B ; 14 \rightarrow 14(14 \rightarrow 28) ; B \rightarrow C: 8 \rightarrow 8$ $(9 \rightarrow 9)$; $B \rightarrow D: 8 \rightarrow 8(19 \rightarrow 26)$; $C \rightarrow D: 8 \rightarrow 8(9 \rightarrow 13)$.

basis of the fact that there is no PG in RDS but a known amount of $P G$ in exogenous surfactant. Since the decay of PG in the lung effluent recovered more than $4 \mathrm{~h}$ after surfactant was exponential, the decay data were used to evaluate the distribution of $\mathrm{PG}$ at zero time. The confidence limits of the phospholipid pools are additionally shown in Table 4 . They are based on $95 \%$ confidence limits of the method used for phospholipid analysis.

Table 4 also shows the ventilatory indexes and SPC/sphingomyelin ratios. Shortly before exogenous surfactant supplementation there was a linear correlation between the ventilatory index and the pool size of surfactant $(r=-0.583, p=0.05)$ and a linear correlation between SPC/sphingomyelin ratio and the apparent pool size $(r=0.784, p<0.01)$.

The apparent turnover rates of surfactant phospholipids after exogenous surfactant were calculated as a product of the fractional turnover rate of PG and the pool size of phospholipids. 


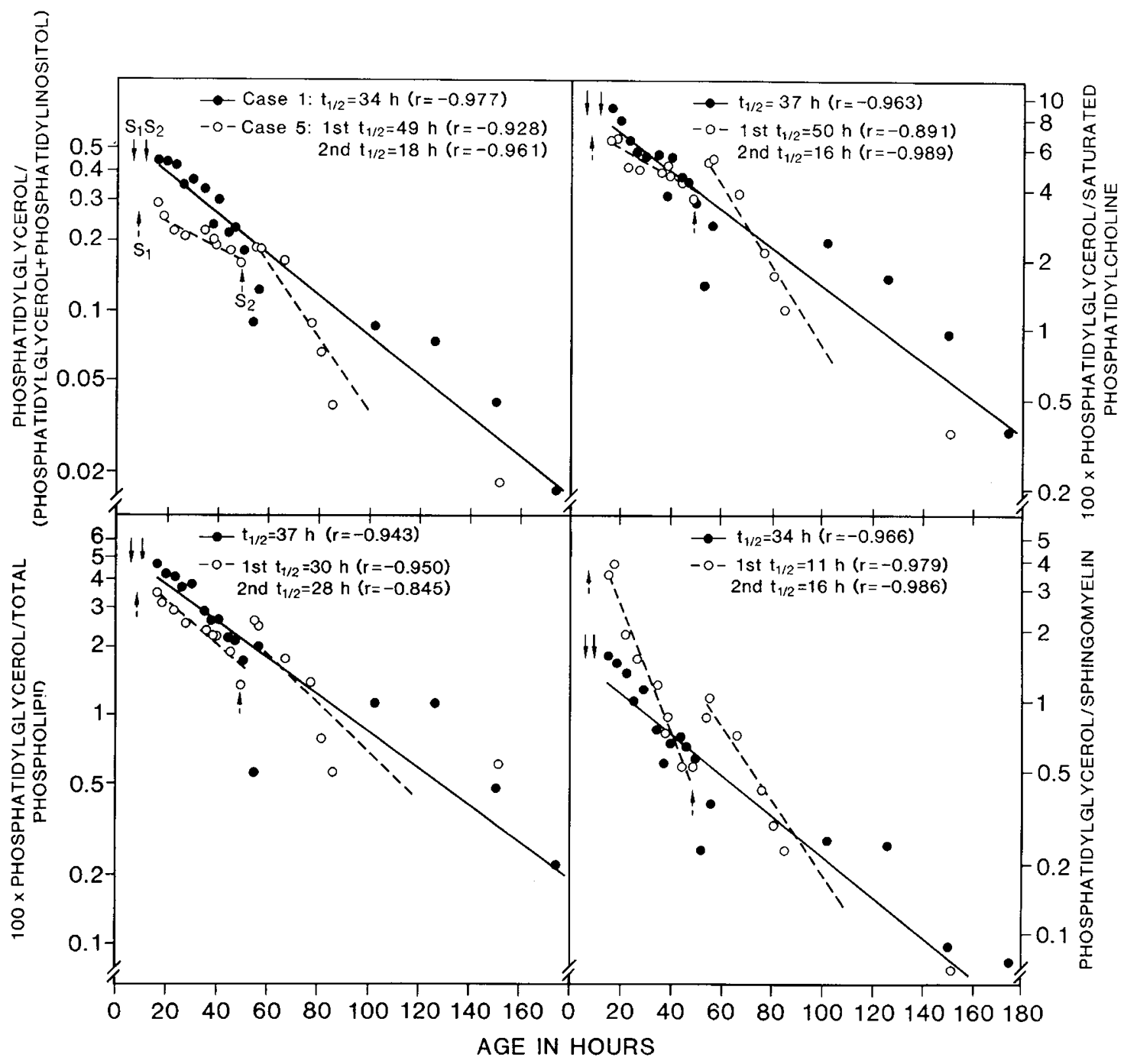

Fig. 3. Disappearance of PG among lung effluent phospholipids after surfactant substitution in two cases. The infants were the same as those presented in Tables 3 and 4 (cases 1 and 5). Case 1, who was treated twice with surfactant had no relapse. The disappearance rate of PG was constant. However, case 5 had the relapse and therefore received a second dose of surfactant. Before the second dose the half-life of PG was equivocal, because the distribution of nonsurfactant phospholipids (sphingomyelin, phosphatidylserine) increased and the surfactant phospholipids decreased.

Table 3. Apparent half-lives of surfactant $P G^{*}$

\begin{tabular}{|c|c|c|c|c|c|c|c|}
\hline \multirow[b]{2}{*}{ Case } & \multirow[b]{2}{*}{ Wt $(\mathrm{g})$} & \multirow[b]{2}{*}{$\begin{array}{c}\text { Gestation age } \\
(\mathrm{wk})\end{array}$} & \multicolumn{5}{|c|}{ Half-life based on a phospholipid index } \\
\hline & & & $P G /(P G+P I)$ & $\mathrm{PG} / \mathrm{SPC}$ & $\begin{array}{c}\text { PG/total } \\
\text { phospholipid }\end{array}$ & PG/sphingomyelin & Mean \\
\hline 1 & 800 & 26 & $34(-0.98)$ & $37(-0.96)$ & $37(-0.94)$ & $34(-0.97)$ & 36 \\
\hline 2 & 750 & 26 & $35(-0.92)$ & $32(-0.88)$ & $27(-0.87)$ & $28(-0.91)$ & 31 \\
\hline 3 & 1060 & 27 & $33(-0.97)$ & $33(-0.99)$ & $33(-0.94)$ & $33(-0.91)$ & 33 \\
\hline 4 & 1210 & 28 & $29(-0.92)$ & $24(-0.89)$ & $28(-0.90)$ & $35(-0.76)$ & 29 \\
\hline $5 a$ & 980 & 28 & $49(-0.93)$ & $50(-0.89)$ & $30(-0.95)$ & $11(-0.98)$ & 35 \\
\hline $5 b$ & 980 & 28 & $18(-0.06)$ & $16(-0.99)$ & $28(-0.85)$ & $16(-0.99)$ & 20 \\
\hline 6 & 1185 & 28 & $32(-0.99)$ & $32(-0.99)$ & $31(-0.97)$ & $28(-0.96)$ & 31 \\
\hline 7 & 700 & 25 & $32(-0.81)$ & $34(-0.65)$ & $24(-0.56)$ & $16(-0.99)$ & 27 \\
\hline 8 & 1040 & 28 & $33(-0.96)$ & $36(-0.93)$ & $27(-0.82)$ & $24(-0.95)$ & 30 \\
\hline 9 & 1240 & 29 & $36(-0.80)$ & $30(-0.80)$ & $24(-0.87)$ & $24(-0.66)$ & 29 \\
\hline 10 & 1400 & 30 & $28(-0.87)$ & $33(-0.92)$ & $25(-0.93)$ & $24(-0.80)$ & 28 \\
\hline Mean & 1034 & 27.5 & 33 & 32 & 29 & 25 & 30 \\
\hline$\pm \mathrm{SE}$ & 73 & 0.5 & 2 & 3 & 1 & 2 & 1 \\
\hline
\end{tabular}

* Cases 1-5 received two doses of surfactant. In cases 1-4 the second dose was given prophylactically within $8 \mathrm{~h}$ from the first dose, whereas case 5 received surfactant during the relapse (Fig. 3). Cases 5 and $7-10$ had a relapse, i.e. the ventilatory index increased by at least $60 \%$ from that present during remission. Tracheal aspirates within $<4 \mathrm{~h}$ after exogenous surfactant were excluded. 
Table 4. Apparent pool size and turnover rate of surfactant phospholipids (phosphatidylcholine, PG, and PI). Effect of surfactant substitution*

\begin{tabular}{|c|c|c|c|c|c|c|c|c|c|}
\hline \multirow[b]{2}{*}{ Case } & \multicolumn{2}{|c|}{$\begin{array}{c}\text { Ventilatory } \\
\text { index } \\
\text { (cm } \mathrm{H}_{2} \mathrm{O} / \mathrm{mm} \\
\mathrm{Hg})\end{array}$} & \multicolumn{2}{|c|}{$\begin{array}{c}\mathrm{SPC} / \\
\text { sphingomyelin } \\
\text { ratio }\end{array}$} & \multicolumn{3}{|c|}{$\begin{array}{l}\text { Apparent pool size of surfactant phospho- } \\
\text { lipids ( } \mu \mathrm{mol}) \text { (confidence limits) }\end{array}$} & \multirow{2}{*}{$\begin{array}{l}\text { Fractional turnover } \\
\text { rate of } \mathrm{PG} \\
\left(\mathrm{h}^{-1}\right)\end{array}$} & \multirow{2}{*}{$\begin{array}{c}\text { Apparent turnover } \\
\text { rate of surfactant phospholipids } \\
\left(\mu \mathrm{mol} \cdot \mathrm{h}^{-1}\right)\end{array}$} \\
\hline & Before & After & Before & After & Endogenous & Exogenous & Total & & \\
\hline 1 & 0.300 & 0.091 & 3.1 & 12.5 & $12(0-31)$ & $132(128-136)$ & $144(128-167)$ & 0.019 & 2.8 \\
\hline 2 & 0.264 & 0.050 & 1.0 & 27.5 & $6(0-22)$ & $130(125-134)$ & $136(125-156)$ & 0.022 & 3.0 \\
\hline 3 & 0.174 & 0.030 & 2.8 & 17.4 & $14(1-31)$ & $147(142-157)$ & $161(143-190)$ & 0.021 & 3.5 \\
\hline 4 & 0.159 & 0.057 & NM & 14.0 & $13(0-30)$ & $154(149-164)$ & $167(149-195)$ & 0.024 & 4.0 \\
\hline 5 & 0.162 & 0.030 & 2.0 & 15.2 & $14(3-23)$ & $65(63-67)$ & $79(66-90)$ & 0.020 & 1.6 \\
\hline 6 & 0.207 & 0.065 & 2.1 & 20.0 & $10(0-28)$ & $74 \quad(71-77)$ & $84(71-105)$ & 0.022 & 1.9 \\
\hline 7 & NM & 0.95 & 1.2 & 14.5 & $0(0-6)$ & $63(61-65)$ & $63(71-74)$ & 0.026 & 1.6 \\
\hline 8 & 0.204 & 0.110 & 1.8 & NM & $7(0-16)$ & $65 \quad(63-67)$ & $72 \quad(63-83)$ & 0.023 & 1.7 \\
\hline 9 & 0.153 & 0.059 & 1.9 & NM & $12(6-18)$ & 74 (71-77) & $86 \quad(77-95)$ & 0.024 & 2.1 \\
\hline 10 & 0.130 & 0.032 & 3.2 & NM & $15(5-24)$ & $88 \quad(85-91)$ & $103(90-115)$ & 0.025 & 2.6 \\
\hline
\end{tabular}

* The severity of RDS [expressed as ventilatory index $\left(\mathrm{FiO}_{2} \times\right.$ mean airway pressure/arterial $\left.\mathrm{pO}_{2}\right)$ ] and SPC/sphingomyelin ratio was measured 0$4 \mathrm{~h}$ before and $4-8 \mathrm{~h}$ after surfactant. Cases $1-4$ received two doses of surfactant. The pool size of endogenous surfactant was calculated on the basis of the Fick principle: the distribution of PG in lung effluent at zero time was extrapolated on the basis of the exponential decay data. The confidence limits of the pool size estimates are based on the accuracy of phospholipid analysis only. Fractional turnover rate of PG was calculated as follows: $1 /(1.44 \times$ half-life of PG). Turnover rate of surfactant phospholipids (pool size $\times$ fractional turnover) was calculated on the assumption that the surfactant phospholipids turn over as a unit (see "Discussion"). NM, Not measurable or unavailable.

The recipients of a double dose (cases $1-4)$ had a significantly higher apparent turnover rate than those infants who received only a single dose of surfactant $(3.3 \pm 0.3$ versus $1.9 \pm 0.2 \mu \mathrm{mol} /$ $\mathrm{h}, p<0.01$ ). This suggests that exogenous surfactant has a positive feedback on surfactant turnover rate

\section{DISCUSSION}

There was a significant negative correlation between the severity of respiratory failure and a surfactant index during the course of RDS. This was true both among the conventionally treated infants and among those whose respiratory course was favorably modified by surfactant supplementation. Accordingly, the surfactant indexes increased during surfactant-induced remission, decreased during a relapse of respiratory failure (present among $50 \%$ of surfactant-treated patients), and increased again during the recovery. Those infants eventually developing bronchopulmonary dysplasia had an inferior surfactant profile early during the course of respiratory failure. These findings support the concept that surfactant is an important determinant of respiratory failure throughout the course of RDS.

The recipients of surfactant tended to have slightly more severe lung disease than the controls, when the results were adjusted by covariance to remove the difference in lung effluent phospholipids. This suggests that the exogenous surfactant is inferior to the endogenous one, perhaps owing to uneven distribution, or that other determinants of respiratory failure in addition to surfactant are important. For instance, high alveolar-capillary permeability, accumulation of surfactant inhibitors in the airways, or epithelial injury with activation of the coagulation or complement pathways may all be interacting with surfactant deficiency to result in lung injury and altered gas exchange. An additional consequence of exogenous surfactant could be a decrease in pulmonary vascular resistance in the absence of ductal closure, resulting in left-to-right ciculatory shunt, cardiac failure, pulmonary edema, and deterioration of lung function. In the present study indomethacin was given early to prevent the adverse consequences of patent ductus ateriosus $(26,27)$. Ductal closure rate with indomethacin was not altered by surfactant treatment.

Although the present evidence suggests that SPC/sphingomyelin ratio correlates with the pool size of surfactant (16), other more accurate approaches are required to define further the surfactant defect and its relationship to respiratory failure. The present attempt to evaluate the turnover and the pool size of surfactant was based upon a specific surfactant marker, PG, that was present in exogenous surfactant, but only little if any $P G$ was detectable in tracheal aspirates among the conventionally treated infants.

The present estimate of the biological half-life and the pool size is based on several assumptions: 1) the distribution of the exogenous surfactant is similar to the distribution of endogenous surfactant; 2) the phospholipid composition in various surfactant compartments is uniform; 3) the surfactant system is pulse labeled; 4) there is no endogenous synthesis of the marker; and 5) the pool size at a time following exogenous surfactant is constant. In the following discussion these assumptions are critically evaluated.

1) Although exogenous surfactant spreads rapidly over large surfaces covering the airways, it is unclear whether its distribution is homogenous in RDS, especially since as a result of the lung damage the airways may become obstructed. According to Jobe et al. (28) exogenous surfactant given to fetal lung liquid of immature lambs (120 days gestation) is homogenously distributed and matched with perfusion. However, when these animals were allowed to develop severe respiratory failure the lungs became only partially aerated following exogenous surfactant, which was preferentially distributed over the aerated and presumably surfactant-treated areas of the lung (28). It may be argued that the respiratory failure among our infants was less severe than in those immature sheep, since the exogenous surfactant improved the respiratory failure for many hours and there was a homogenous aeration in most cases as indicated by chest radiographs $(23,29)$, whereas in immature lambs the improvement in respiratory failure only lasted $3 \mathrm{~h}(30)$. We measured the surfactant pool size in preterm rabbits using two techniques. Surfactant was either recovered from the bronchoalveolar lavage and the lamellar body fraction, or the pool was estimated by the Fick principle using $\mathrm{PG}$ as a marker of exogenous surfactant. The latter method (used in the present study) gave a higher estimate of the pool size (unpublished data). This difference can be due to either inappropriately fast disappearance of exogenous surfactant marker from the airways or to incompleteness of the recovery of the total surfactant pool by combining the lavage and the lamellar body fraction. At present it is unknown which of the two estimates is more accurate, and we cannot define the pool into which surfactant PG was distributed in infants with RDS.

2) According to current evidence there is a bidirectional flux 
of intact surfactant phospholipids between alveolar space and the lamellar bodies (12-14). In a 3-day rabbit about $90 \%$ of the phosphatidylcholine secretion from lamellar bodies to alveolar lining is likely to be due to reutilization of intact phospholipids. The rest is due to secretion of newly synthesized phosphatidylcholine (31). In adult rabbits the phospholipids of intra- and extracellular surfactants were similar (32), and a surfactant marker applied to the airways equilibrated within a few hours between intra- and extracellular pools (12). Although reutilization of phosphatidylcholine is active in young rabbits and surfactant phospholipids are taken up by immature lung parenchyma (33), it is unclear whether $P G$ is reutilized during the present measurements. According to Jacobs et al. (34) the efficiency of PG reutilization was less than that of phosphatidylcholine. In the present study we found that, $4 \mathrm{~h}$ after exogenous surfactant, the disappearance rate of $\mathrm{PG}$ became single exponential, suggesting either that the reutilization is fast enough to allow equilibrium between intracellular and extracellular surfactant pools or that reutilization of $P G$ is small enough not to interfere with calculation of the apparent half-life.

3) The use of labeled precursors for the estimation of the biological half-life of surfactant components is hampered by the fact that the surfactant is not pulse labeled $(12,18)$. The present approach of directly applying an intact phospholipid label into the airways should improve the pulse labeling (25).

4) Endogenous synthesis of the marker prolongs the actual biological half-life. This is not the problem of the present analysis, since PG was not detectable before surfactant substitution either in the fetal amniotic fluid or in the initial tracheal aspirate. Furthermore, significant synthesis of PG was very unlikely because high serum myoinositol concentration found in our patients (data not shown) favors PI instead of PG synthesis (12).

5) According to animal studies the pool size of the lavageable surfactant increases several-fold within a few hours after preterm delivery $(33,35,36)$. Thereafter the increase is more gradual (34). There are no data on the postnatal changes in the pool size of human surfactant, although it is likely to increase after birth in $\operatorname{RDS}(9,10,37)$. SPC/sphingomyelin ratio that positively correlates with the pool size of surfactant (16) also increased (Table 1). However, there was little further change in SPC/ sphingomyelin ratio after the low SPC/sphingomyelin ratio was increased after exogenous surfactant. The disappearance rates of PG in supplemented infants without relapse of respiratory failure were similar regardless of whether the half-lives were expressed on the basis of surfactant or nonsurfactant reference. Therefore, in these cases the pool size surfactant may remain stable during a few days after substitution, allowing accurate estimate of the half-life. Conversely in the five cases that had a relapse of the respiratory failure the apparent half-lives were faster when $\mathrm{PG}$ was expressed on the basis of nonsurfactant reference. In these cases the surfactant system may be in a nonsteady state, and therefore the apparent half-lives were ambiguous.

It may also be argued that the disappearance of PG and concomitant increase in PI represents functionally a nonsteady state. However, PI can replace PG in adults (38) and in fetuses (39) without deterioration or surfactant function. We believe that the present estimate of the biological half-life of PG in RDS is as accurate as similar techniques using radioactive precursors. The result may not be generalized to include other surfactant components, since although phosphatidylcholine and PG have a similar half-life in animals $(12,18)$, the whole complex may not turn over as a unit $(12,18,20,40,41)$.

A remarkable finding of the present study was that although the estimated pool size of surfactant correlated with the severity of RDS, the biological half-life of surfactant phospholipid varied surprisingly little after surfactant substitution. Those patients who received twice the surfactant dose of $60 \mathrm{mg} / \mathrm{kg}$ (minimum of $60 \mathrm{mg}$ ) tended to have twice as high pool size as those that were treated once, because the endogenous pool was small compared with the exogenous one (Table 4). The second dose appar- ently did not prolong the half-life, suggesting that the turnover rate was increased and that the endogenous secretion was stimulated in the presence of abundant surfactant pool. This is consistent with the notion that after the high dosage, the SPC/ sphingomyelin ratio remained high and the relapse of the respiratory failure was less frequent than after a single surfactant dose $(23,42)$. Although $50 \mathrm{mg} / \mathrm{kg}$ surfactant to preterm lambs caused a maximal acute improvement in respiratory function (43), more surfactant may be needed to treat severe RDS.

The molecular basis and the quantitative aspects of the alleged positive feedback between the surfactant pool size and its turnover rate remain unclear. Surfactant substitution improves alveolar ventilation. On a short-term basis an increased ventilation could increase both exocytosis and reuptake of surfactant into alveolar cells (44). Extra surfactant may provide a rate limiting substrate for synthesis. Clearly, the present and previous data $(45,46)$ contradict the possibility that exogenous surfactant in RDS inhibits endogenous synthesis and secretion.

Acknowledgements. The authors thank the nurses of the newborn intensive care unit in Children's Hospital, University of Helsinki, and in Infant Special Care Unit, University of California, San Diego, for collecting the tracheal aspirates. We also thank E. Riihelä, H. Ahola, and K. Holcomb for skillful technical assistance and A. Lehtonen for typing the manuscript.

\section{REFERENCES}

1. Enhörning G, Robertson B 1972 Lung expansion in premature rabbit fetus after tracheal deposition of surfactant. Pediatrics 50:58-66

2. Fujiwara T, Maeta J, Chida S, Morita T, Watabe Y, Abe A 1980 Artificial surfactant for treatment of hyaline membrane disease. Lancet 1:55-59

3. Chu L, Clements JA, Cotton EK, Klaus MH, Sweet AY, Tooley WH 1967 Neonatal pulmonary ischemia. I. Clinical and physiological studies. Pediatrics 40:709-782

4. Gitlin JD, Parad R, Taeusch Jr. HW 1984 Exogenous surfactant therapy in hyaline membrane disease. Semin Perinatol 8:272-282

5. Possmayer F 1984 Biochemistry of pulmonary surfactant during fetal development and in the neonatal period. In: Robertson B, Van Golde LMG, Batenburg JJ (eds) Pulmonary Surfactant. Elsevier, Amsterdam, pp 295-355

6. Avery ME, and Mead J 1959 Surface properties in relation to atelectasis and hyaline membrane disease. Am J Dis Child 97:517-523

7. Adams FH, Fujiwara T, Emmanoulides G, Räihä N 1970 Lung phospholipid of human fetuses and infants with and without hyaline membrane disease. J Pediatr 77:833-841

8. Hallman M 1984 Antenatal diagnosis of lung maturity. In: Robertson B, Van Golde LMG, Batenburg JJ (eds) Pulmonary Surfactant. Elsevier, Amsterdam, pp 419-448

9. Shelley SA, Kovacevic M, Paciga JE, Balis JV 1979 Sequential changes of surfactant phosphatidylcholine in hyaline membrane disease of the newborn. N Engl J Med 300:112-116

10. Gluck L, Kulovich MV, Eidelman AI, Cordero L, Khazin AF 1972 Biochemical development of surface activity in mammalian lung. IV. Pulmonary lecithin synthesis in the human fetus and newborn and etiology of the respiratory distress syndrome. Pediatr Res 6:81-99

11. Hallman M. Feldman BH, Kirkpatrick E, Gluck L 1977 Absence of phosphatidylglycerol $(P G)$ in respiratory distress in the newborn. Pediatr Res 11:714720

12. Hallman M, Epstein BL, Gluck L 1981 Analysis of labeling and clearance of lung surfactant phospholipids in the rabbit. Evidence of bidirectional surfactant flux between lamellar bodies and alveolar lavage. J Clin Invest 68:742751

13. Jacobs H, Jobe A, Ikegami M. Conaway D 1983 The significance of reutilization of surfactant phosphatidylcholine. J Biol Chem 258:4156-4165

14. Baritussio AG, Magoon MW, Goerke J, Clements JA 1981 Precursor-product relationship between rabbit type II cell lamellar bodies and alveolar surfaceactive material. Surfactant turnover time. Biochim Biophys Acta 666:382393

15. Jacobs H, Jobe A, Ikegami M, Miller D, Jones S 1984 Reutilization of phosphatidylcholine analogues by the pulmonary surfactant system. The lack of specificity. Biochim Biophys Acta 793:300-309

16. Hallman M, Arjomaa P, Tahvanainen J, Lachmann B, Spragg R 1985 Endobronchial surface active phospholipids in various pulmonary diseases. Eur $\mathrm{J}$ Respir Dis 67(suppl 142): 37-47

17. Tierney DF, Clemens JA. Trahan HJ 1967 Rates of replacement of lecithins and alveolar instability in rat lungs. Am J Physiol 213:671-676

18. Jobe A, Kirkpatrick E, Gluck L 1978 Labeling of phospholipids in the surfactant and subcellular fractions of rabbit lung. J Biol Chem 253:3810-3816

19. Jobe A. Ikegami M, Sarton-Miller I 1980 The in vivo labeling with acetate and palmitate of lung phospholipids from developing and adult rabbits. Biochim Biophys Acta 617:65-75 
20. King RJ, Martin H 1980 Intracellular metabolism of the apoproteins of pulmonary surfactant in rat lung. J Appl Physiol 48:812-820

21. Jobe A. Ikegami M. Sarton-Miller I, Barajas L 1980 Surfactant metabolism of newborn lamb lungs studied in vivo. J Appl Physiol 49:1091-1098

22. Ikegami M, Jobe A. Nathanielsz PW 1981 The labeling of pulmonary surfactant phosphatidylcholine in newborn and adult sheep. Expt Lung Res 2:197-206

23. Hallman M, Merritt TA, Järvenpää A-L, Boynton B, Mannino F, Gluck L, Moore T. Edwards D 1985 exogenous human surfactant for treatment of severe respiratory distress syndrome: a randomized prospective trial. J Pediatr 106:963-969.

24. Mason RJ. Nellenbogen J, Clements JA 1976 Isolation of disaturated phosphatidylcholine with osmium tetroxide. $\boldsymbol{J}$ Lipid Res 17:281-284

25. Zilversmit DB, Entenman C, Fishler MC, Chaikoff IL 1943 The turnover rate of phospholipids in the plasma of the $\operatorname{dog}$ as measured with radioactive phosphorus. J Gen Physiol 26:333-340

26. Mahony L, Carnero V. Brett C, Heymann MA, Clyman RJ 1982 Prophylactic indomethacin therapy for patent ductus arteriosus in very low birth weight infants. N Engl J Med 306:506-510

27. Merritt TA, Harris JP, Roghmann K, Wood B, Campanella V, Alexon C, Manning J, Shapiro DL 1981 Early closure of the patent ductus arterious in very low birthweight infants: controlled trial. J Pediatr 99:281-286

28. Jobe A. Ikegami M. Jacobs H, Jones S 1984 Surfactant and pulmonary blood flow distribution following treatment of premature lambs with natural surfactant. J Clin Invest 73:848-856

29. Edwards DK, Hilton SW, Merritt TA, Hallman M, Mannino F, Boynton BR 1985 Human surfactant treatment of respiratory distress syndrome. Influence on the radiolographic course of respiratory distress syndrome. Radiology 157:329-334

30. Jobe A, Ikegami M. Glatz T, Yoshida Y, Diakomanolis E, Padbury J 1981 Duration and characteristics of treatment of premature lambs with natural surfactant. J Clin Invest 67:370-375

31. Jacobs HC. Jobe AH, Ikegami M. Jones S 1982 Surfactant phosphatidylcholine source, fluxes, and turnover times in 3-day old, 10-day old, and adult rabbits. J Biol Chem 257:1805-1810

32. Hallman M, Gluck L 1975 Phosphatidylglycerol in lung surfactant. II. Subcellular distribution and mechanism biosynthesis in vitro. Biochim Biophys Acta 409:172-191

33. Jacobs HC, Jobe AH, Ikegami M, Jones SJ 1985 Accumulation of alveolar surfactant following delivery and ventilation of premature lambs. Expt Lung
Res 8:125-140

34. Jacobs HC, Jobe A, Ikegami M. Jones S 1985 Reutilization of phosphatidylglycerol and phosphatidylethanolamine by the pulmonary surfactant system in 3-day-old rabbits. Biochim Biophys Acta 843:172-179

35. Gluck L, Landowne RA, Kulovich MV 1970 Biochemical development of surface activity in mammalian lung. III. Structural changes in lung lecithin during development of the rabbit fetus and newborn. Pediatr Res 4:352-364

36. Jobe A, Ikegami M, Jacobs H, Jones S 1983. Surfactant pool size and severity of RDS in prematurely delivered lambs. Am J Respir Dis 127:751-755

37. Balis JV, Delivoria M, Correco PE 1966 Maturation of postnatal human lung and the idiopathic respiratory distress syndrome. Lab Invest 15:530-546

38. Beppu OS, Clements JA, Goerke J 1983 Phosphatidylglycerol-deficient lung surfactant has normal properties. J Appl Physiol 55:496-502

39. Hallman M, Enhorning G, Possmayer F 1985 Composition and surface activity of normal and phosphatidylglycerol-deficient lung surfactant. Pediatr Res 19:286-292

40. Magoon MW, Wright JR, Baritussio A, Williams MC, Goerke J, Benson BJ Hamilton RL, Clements JA 1983 Surfractionation of lung surfactant. Implications for metabolism and surface activity. Biochim Biophys Acta 750:1831

41. Jobe $\mathrm{AH}$, Jacobs HC 1984 Catabolism of pulmonary surfactant. In: Robertson B, Van Golde LMC, Batenburg JJ (eds) Pulmonary Surfactant. Elsevier, Amsterdam, pp 271-293

42. Hallman M, Merritt TA, Cochrane CG, Gluck L 1984 Human surfactant substitution in severe respiratory distress syndrome. Prog Respir Res 18:193203

43. Ikegami M. Adams FH, Towers B, Osher A 1980 The quantity of natural surfactant necessary to prevent the respiratory distress syndrome in premature lambs. Pediatr Res 14:1082-1085

44. Truog WE 1984 Surface active material: influence of lung distension and mechanical ventilation on secretion. Semin Perinatol 8:300-307

45. Stewart-DeHaan PJ, Metcalfe IL, Harding PGR, Enhörning G, Possmayer F 1980 Effect of birth and surfactant treatment on phospholipid synthesis in the premature rabbit. Biol Neonate 38:238-247

46. Jobe A Ikegami M, Glatz T, Yoshida Y, Diakomanolis E, Padbury J 1983 Saturated phosphatidylcholine secretion and the effect of natural surfactant on premature and term lambs ventilated for 2 days. Exp Lung Res 4:259267 